\title{
STRUCTURE AND FUNCTION OF PALLADIN'S ACTIN BINDING DOMAIN
}

\author{
Moriah R. Beck ${ }^{1,2,3}$, Richard D.S. Dixon ${ }^{1,2}$, Silvia M. Goicoechea ${ }^{4, a}$, Grant S. Murphy ${ }^{1}$, \\ Joseph G. Brungardt ${ }^{3}$, Matthew T. Beam ${ }^{1}$, Pavan Srinath ${ }^{1}$, Julie Patel ${ }^{4}$, Jahan Mohiuddin ${ }^{4}$, \\ Carol A. Otey ${ }^{2,4}$, and Sharon L. Campbell ${ }^{1,2}$ \\ Moriah R. Beck: moriah.beck@wichita.edu; Richard D.S. Dixon: rdixon@kbibiopharma.com; Silvia M. Goicoechea: \\ Silvia.Goicoechea@utoledo.edu; Grant S. Murphy: g.s.murphy@gmail.com; Joseph G. Brungardt: \\ josephbrungardt@gmail.com; Matthew T. Beam:mtbeam@email.unc.edu; Pavan Srinath: pavan.srinath@gmail.com; \\ Julie Patel: pateljb@email.unc.edu; Jahan Mohiuddin: jahan.mohiuddin@gmail.com; Carol A. Otey: \\ carol_otey@med.unc.edu; Sharon L. Campbell: campbesl@med.unc.edu \\ ${ }^{1}$ Department of Biochemistry and Biophysics, University of North Carolina School of Medicine, \\ 120 Mason Farm Rd., Chapel Hill, North Carolina 27599, USA \\ ${ }^{2}$ Lineberger Comprehensive Cancer Center, University of North Carolina School of Medicine, 120 \\ Mason Farm Rd., Chapel Hill, North Carolina 27599, USA \\ ${ }^{3}$ Chemistry Department, Wichita State University, 1845 Fairmount St., Wichita, Kansas 67260, \\ USA \\ ${ }^{4}$ Department of Cell Biology and Physiology, University of North Carolina School of Medicine, 120 \\ Mason Farm Rd., Chapel Hill, North Carolina 27599, USA
}

\section{Abstract}

Here we report the NMR structure of the actin-binding domain contained in the cell adhesion protein palladin. Previously we demonstrated that one of the immunoglobulin domains of palladin (Ig3) is both necessary and sufficient for direct F-actin binding in vitro. In this study, we identify two basic patches on opposite faces of Ig3 that are critical for actin binding and crosslinking. Sedimentation equilibrium assays indicate that the Ig 3 domain of palladin does not self-associate. These combined data are consistent with an actin crosslinking mechanism that involves concurrent attachment of two actin filaments by a single palladin molecule by an electrostatic mechanism. Palladin mutations that disrupt actin binding show altered cellular distributions and morphology of actin in cells, revealing a functional requirement for the interaction between palladin and actin in vivo.

\section{(C) 2013 Elsevier Ltd. All rights reserved.}

Address correspondence to: Moriah R. Beck, Department of Chemistry, Wichita State University, 1845 Fairmount St., Wichita, KS, USA, Tel: (316) 978-5476; Fax: (316) 978-3431; moriah.beck@ wichita.edu or Sharon L. Campbell, Department of Biochemistry and Biophysics, University of North Carolina at Chapel Hill, Chapel Hill, NC, USA, Tel: (919) 966-7139; Fax: (919) 966-2852; campbes1@med.unc.edu.

aPresent address: Department of Biological Sciences, University of Toledo, Toledo, OH 43606

This is a PDF file of an unedited manuscript that has been accepted for publication. As a service to our customers we are providing this early version of the manuscript. The manuscript will undergo copyediting, typesetting, and review of the resulting proof before it is published in its final citable form. Please note that during the production process errors may be discovered which could affect the content, and all legal disclaimers that apply to the journal pertain.

Accession Numbers

The structure of palladin's Ig3 domain determined by these authors has been deposited in the PDB ID: 2LQR. NMR restraints have also been deposited in the BMRB ID: 15512. During the work described in this manuscript another structure for the same domain of palladin was deposited by the RIKEN structural genomics initiative (PDB ID: 2DM2). 


\section{Introduction}

As one of the most abundant proteins in the cell, actin participates in many important cellular processes including cell motility, maintenance of cell shape, cell division, and muscle contraction. Actin filaments can be assembled into diverse structures, such as the tight bundles that support microvilli or stereocilia, or the highly dynamic actin networks that are required for protrusive cell motility. ${ }^{1}$ The mechanism by which the cell coordinates the assembly of each type of actin filament array is not fully understood, although numerous key players have been identified. ${ }^{2,3}$ Currently over 150 actin-binding proteins (ABPs) have been identified that influence localization, polymerization dynamics, crosslinking, and organization of actin. ${ }^{4}$ These ABPs have various means of regulating actin, which include the ability to sequester monomeric actin (G-actin), nucleate filament formation, sever filamentous actin (F-actin), generate branched arrays of actin, and cap actin filaments. Moreover there are currently only a few known actin-binding motifs: the calponin homology $(\mathrm{CH}),{ }^{5}$ the Wiskott-Aldrich syndrome homology (WH2) module, ${ }^{6}$ the gelsolin homology, ${ }^{7}$ and the actin depolymerizing factor (ADF-H) domains. ${ }^{8}$ There are currently only a limited number of structures of complexes of actin with ABPs, so a better structural understanding of how ABPs interact with actin is still highly sought-after.

Palladin is highly conserved among vertebrate species and is a key regulator of actin organization within migrating cells. ${ }^{9}$ Palladin is ubiquitously expressed in embryonic tissues and is critical for normal development. ${ }^{9}$ Recently, we demonstrated that palladin is able to both bind and bundle actin filaments in vitro and determined that one of the immunoglobulin domains (Ig3) is an actin-binding domain. ${ }^{10}$ Current evidence suggests that palladin occupies an unusual functional niche with roles as both an actin-crosslinking protein and a molecular scaffold that binds several other actin-regulating proteins. ${ }^{10,11}$

Palladin exists as multiple isoforms that are differentially expressed in various tissues, and each isoform contains three to five copies of a distinctive Ig-like domain (Supplemental Fig. S1). Ig domains are typically about 100 amino acids and consist of seven to nine $\beta$-strands that adopt a sandwiched $\beta$-sheet fold. In addition to being the signature domain of the palladin protein family, similar Ig domains have been described in a small number of other vertebrate intracellular proteins, including myomesin, ${ }^{12}$ titin, ${ }^{13} \mathrm{MyBP}-\mathrm{C},{ }^{14} \mathrm{MyBP}-\mathrm{H},{ }^{14}$ and filamin A (FLNa). ${ }^{15}$ The majority of these Ig-containing proteins are specifically expressed in striated muscle, suggesting that this particular type of Ig domain may play a unique role in creating the highly ordered cytoskeleton of the sarcomere. ${ }^{14,16}$ Consistent with this premise, inherited forms of heart disease are associated with mutations affecting the Ig domains of myopalladin, ${ }^{17}$ titin, ${ }^{18,}{ }^{19}$ and MyBP-C. ${ }^{20}$ Recent findings have shown high avidity F-actin binding sites contained within tandem Ig domains of the nonmuscle F-actin crosslinking protein FLNa, in addition to the low affinity conserved F-actin binding domains (ABDs). ${ }^{21}$ This highlights a new role for cytoskeletal Ig domains in directly binding F-actin, however these studies did not identify the specific binding site on FLNa.

Palladin is a member of a subfamily of cytoskeletal proteins, all of which contain tandem Iglike domains, but are encoded as separate genes that are expressed in a more restricted pattern: myopalladin is found only in heart and skeletal muscle 22 and myotilin is expressed mostly in skeletal muscle. ${ }^{23}$ The precise molecular function of palladin family Ig domains has been a matter of debate recently. Myotilin has been shown to bind directly to F-actin, to promote the bundling of actin in vitro, and moreover, generates unusual, super-robust actin bundles in transfected cells. ${ }^{24}$ This overexpression phenotype is similar to that of palladin. ${ }^{24,} 25$ Previous studies utilizing purified myotilin have identified the C-terminus, containing two Ig domains, as the minimal F-actin binding fragment; but did not categorize the binding site on myotilin further. This further motivated us to perform our own detailed 
analysis of palladin's actin-binding activity. We recently showed that full-length purified palladin binds directly to F-actin and crosslinks F-actin into bundles. Furthermore we revealed that palladin's Ig3 domain binds directly to F-actin, while the isolated Ig domains 4 and 5 do not, and that a palladin fragment containing the tandem $\operatorname{Ig} 3-\operatorname{Ig} 4$ domains efficiently bundles actin. ${ }^{10}$ These previous results were the first to show that palladin directly organizes actin into multi-filament arrays, and that certain sub-types of Ig domains are actin-binding modules. However, it is currently unclear how palladin interacts with and bundles F-actin and to what extent this interaction contributes to its role in regulating cell morphology and motility.

In this work, we set out to elucidate the structure of the Ig3 domain of palladin, and thus establish the basis for understanding its interaction with F-actin. Here, we present the NMR solution structure of the palladin Ig3 domain. Structure-guided mutagenesis, coupled with biochemical and cellular studies, reveal that palladin contains two F-actin binding sites that are critically involved in targeting palladin to the actin cytoskeleton.

\section{Results}

\section{Solution structure of Ig3 domain of palladin reveals two solvent-exposed basic patches}

We determined the structure of the palladin Ig3 domain as a first step toward identifying the actin-binding sites on the surface of palladin. In our earlier work, we assigned the complete backbone and side chain resonances of Ig3. ${ }^{26}$ Assignment of NOEs and Ig3 structure determination were accomplished by use of the CYANA program. ${ }^{27,} 28$ CS-Rosetta was used to refine the structures. The lowest scoring models from CS-Rosetta were quite similar to the initial models, however the hydrogen bond network is more complete and the $\mathrm{N}$ - and C-terminal regions converged to a well-packed conformation (Fig. 1a \& b). The final structural statistics are summarized in Table 1. Fig. 1b shows a set of converged structures of the palladin Ig 3 domain. The 20 conformers representing the structures of Ig 3 could be superimposed with RMSD values of $0.7 \AA$ (backbone atoms) and $1.0 \AA$ (heavy atoms) for ordered residues 6-100. The coordinates of the 20 energy-refined conformers that represent the Ig3 solution structure were deposited (PDB ID: $\underline{\mathbf{2 L Q R}}$ )

The overall structure of Ig3 maintains the highly conserved Ig superfamily beta sandwich. The upper $\beta$-sheet contains strands A, B, E, and D; while the lower $\beta$-sheet contains strands $\mathrm{A}^{\prime}, \mathrm{C} / \mathrm{C}^{\prime}, \mathrm{F}$, and $\mathrm{G}$. Members of the I-set of Ig domains typically contain two discontinuous strands, $\mathrm{A} / \mathrm{A}^{\prime}$ and $\mathrm{C} / \mathrm{C}^{\prime}$ as observed here. In the Ig3 domain of palladin, these irregular sections of the structure contain exposed basic residues (side chains highlighted in Fig. 1a) that form two basic patches on the surface (Fig. 1c \& d). The lysine residues contained in these basic patches of Ig3 are not in conserved positions when compared to the other Ig domains of palladin, but are conserved with similar domains of palladin family members (Supplemental Fig. S1b). We also note that the geometry of the $\beta$-strand at Tyr 17 is atypical, where the burial of the side chain induces a kink in the strand. While the interior of the $\beta$-sandwich contains two cysteine residues ( 29 and 93) whose geometries could support a disulfide bond, the presence of reducing agent in the NMR sample and the $C \beta$ chemical shifts for these residues indicate that a disulfide is not present in this structure.

Previously, when we reported that the Ig3 domain of palladin was able to bind F-actin directly, we presented a homology model of the Ig3 domain based on the I1 domain of titin (PDB ID: 1G1C). ${ }^{10}$ We predicted that the palladin Ig3 domain was an I-type immunoglobulin-like domain and proposed that the interaction surface created by the amino acid sequence, rather than large scale alterations of the I-type Ig fold, were responsible for the association with F-actin. The NMR solution structures of the palladin Ig3 domain from human (PDB ID: 2DM2) was recently deposited and the mouse (PDB ID: $\mathbf{2 L Q R}$ ) as 
presented here, which both confirm that the Ig3 domain has the structural features of an Itype Ig domain, as presented in the homology model. Alignment of the two NMR solution structure ensembles (Supplemental Fig. S2) shows the same protein fold for the two structures, although some minor differences can be seen in the flexible regions of the domain. The NMR solution structure of the palladin Ig3 domain and the identification of basic patches support our previous speculation regarding the protein fold of Ig3 and adaptations for binding to $\mathrm{F}$-actin.

\section{Basic patches are involved in actin binding}

There are several positively charged residues on two opposite faces of Ig3 (Fig. 1c \& d). Such clustering of positively charged residues occurs on several other F-actin binding proteins, namely AFAP-110 (614-617), thymosin $\beta 4$ (17-20), villin (818-821), fascin (K22, $\mathrm{K} 43$, and R398) ${ }^{29}$ and vasodilator stimulated phosphoprotein, also known as VASP (234237). ${ }^{30}$ Many of these actin binding proteins also contain a consensus sequence of (K-L-K/ $\mathrm{R}-\mathrm{K}$ ) and the motif is known as actin-binding domain 3 (ABD3). ${ }^{31}$ Likewise, the Ig3 domain of palladin contains a similar lysine-rich motif $\left(\mathrm{K}_{13}-\mathrm{L}-\mathrm{K}_{15}-\mathrm{H}-\mathrm{Y}-\mathrm{K}_{18}\right)$ in one of the surface basic patches. These lysine residues are not found in the other Ig domains of palladin that do not bind directly to F-actin, as highlighted in supplemental Fig. S1a. To test whether actin binding involves basic residues, we made single, double, and triple lysine mutants (K15A, K18A, K15/18A, K36A, K38A, K36/38A, K51A, and K15/18/51A) in Ig3, thus neutralizing the charge of five residues on this surface. Actin binding and bundling activities of the palladin mutants were assessed using co-sedimentation with F-actin. As shown in Fig. $2 \mathrm{a} \& \mathrm{~b}$ (and Supplemental Fig. S3), F-actin binding was reduced significantly ( $\mathrm{P}<0.05$ for means, $t$ test) for mutations of lysine residues 15,18 , and 51 , yet mutations to either basic patch do not completely eliminate binding. In contrast, a K36/38A mutant failed to reduce F-actin binding (Supplemental Fig. S3). These results suggest that the Ig3 domain of palladin contains two major actin-binding patches (K15/K18 and K51) that are important for direct binding interactions with F-actin.

\section{Lysine mutations do not alter lg3 conformation}

To determine whether mutations to the basic patches on Ig3 produce local or global perturbations to the structure and dynamics of the protein, we employed $2 \mathrm{D}^{1} \mathrm{H}_{-}{ }^{15} \mathrm{~N}$ HSQC NMR. We did not detect any significant changes in either the chemical shifts or intensities of the NH peaks when comparing the peaks observed in the WT and mutant protein (K15/18/51A Ig3) HSQC spectra (See supplemental Fig. S4). Only minor NH chemical shift changes are observed in the HSQC spectrum of the K15/18/51A Ig3 variant compared with WT Ig3 for residues proximal to the mutated lysine residues. Overall the ${ }^{1} \mathrm{H}_{-}{ }^{15} \mathrm{~N}$ HSQC $2 \mathrm{D}$ NMR spectrum of the lysine triple mutant overlays well with WT Ig3, indicating that these mutations do not alter the structural integrity of the immunoglobulin fold.

\section{Ig3 is sufficient for bundling actin}

To determine the effect these lysine mutations have on the crosslinking activity of palladin, differential sedimentation assays were used to detect actin bundles. Previous studies demonstrated that the tandem Ig3-Ig4 domain is the minimal fragment of palladin required for F-actin crosslinking. This work also revealed that the tandem Ig3-Ig4 domain exhibited enhanced affinity for F-actin, over that of the Ig3 domain alone. However, the isolated Ig4 domain did not bind F-actin. ${ }^{10}$ Conversely, in our latest co-sedimentation assays, we observed significant amounts of crosslinked F-actin in the presence of Ig3, with increasing Ig3 concentration correlated with an increase in the amount of bundled F-actin (Fig. 3a \& b). One difference is that the original data was conducted at only one Ig 3 concentration, thereby limiting the binding capacity. ${ }^{10}$ In addition, close inspection of this previously published data reveals levels of F-actin in the Ig3 bundles above actin only background levels The 
bundling data we present here for Ig3 shows a concentration dependence, where increasing amounts of F-actin are found in the bundled pellet as the concentration of Ig3 is increased. This is similar to what was previously reported for the Ig3-Ig4 differential sedimentation assay, however, the apparent $\mathrm{K}_{\mathrm{d}}$ for Ig3 is much weaker than that of Ig3-Ig4 (Supplemental Fig. S5). We also observed bundles formed by Ig3 using fluorescence microscopy with these altered ratios of actin:Ig3 (1:2 versus previous 1:1) (Supplemental Fig. S6). These bundles appeared to be smaller than those observed for the tandem Ig3-Ig4, but were consistently detected. These results indicate that while Ig3 is the minimal domain required for binding and bundling of F-actin, that Ig4 plays an important, supplementary role in producing larger, more complex bundles.

We next assessed the ability of the Ig3 lysine mutants to bundle actin using the cosedimentation assay. We quantified the relative amount of F-actin being bundled among three mutant constructs. As shown in Fig. 3c \& d, mutations to either basic patch containing $\mathrm{K} 15 / 18 \mathrm{~A}$ or K51A, decreased actin bundling to that of F-actin alone background levels. While mutating any of these lysine residues individually did not result in complete loss of Factin binding, it does result in complete loss of F-actin bundling. This indicates that loss of binding at either site disrupts bundling and suggests that crosslinking occurs through engagement of two actin filaments via two separate binding sites on the Ig3 domain.

\section{Immunoglobulin domains of palladin remain monomeric in solution}

To probe whether the Ig3 and/or Ig4 domains of palladin exist in solution as monomers, we determined the native molecular mass of both the isolated domains as well as the tandem Ig3-Ig4 domains. Sedimentation equilibrium data were collected at three different rotor speeds and at three different protein concentrations (10, 20, and $40 \mu \mathrm{M})$. Single, ideal species analysis of individual traces was performed using nonlinear, least-squares analysis (NLLS) to determine the apparent molecular mass and effective oligomerization state of the Ig domains of palladin. The concentration profiles and fits to the observed traces when using a single-species model reveal that Ig3, Ig4 and tandem Ig3-Ig4 are all monomeric in solution (Supplemental Fig. S7). At each loading concentration, the average molecular mass was not significantly different than that predicted for the monomer and did not increase with increasing concentration of protein. By analytical ultracentrifugation, we did not detect any oligomers as highlighted in Table 2.

\section{Palladin's Ig3 domain plays a critical role in subcellular targeting}

Endogenous $90 \mathrm{kD}$ palladin has been shown to exhibit two distinct subcellular localization patterns: cytoplasmic and nuclear. ${ }^{32,33}$ Cytoplasmic palladin is largely concentrated within actin-rich structures. ${ }^{9}, 34,35 \mathrm{We}$ set out to test the hypothesis that palladin's binding to Factin is required to maintain its localization within the cytoplasm. Single, double and triple point mutations (K15A, K18A, K15/18A, K51A, and K15/18/51A) were introduced into a plasmid encoding full-length GFP-tagged palladin and transfected into cultured COS-7 cells. Two days after transfection, the cells were fixed, counter-stained with phalloidin to detect Factin and DAPI to detect the nuclei, and imaged. Metamorph image analysis software was used to quantify the amount of palladin that co-localized with DAPI in the nucleus. The results showed that palladin containing single point mutations (K15A, K18A, K51A) retains a persistently cytoplasmic localization pattern (Fig. 4 and supplemental Fig. S8). However, the double and triple point mutants (K15/18A, K15/18/51A) displayed a strongly nuclear localization pattern in $98-100 \%$ of the transfected cells, suggesting the possibility that palladin may be imported into the nucleus if the binding of palladin to actin is insufficiently robust to retain it in the cytoplasm. To test this hypothesis, we designed a plasmid encoding GFP-palladin with the entire $\operatorname{Ig} 3$ domain deleted $(\Delta \operatorname{Ig} 3)$. Somewhat surprisingly, the localization of the $\Delta \operatorname{Ig} 3$ mutant was largely diffuse, as it did not co-localize with either 
actin-rich structures nor was it efficiently localized to the nucleus (Fig. 4). These results suggest that palladin's Ig3 domain may interact with a second binding partner, in addition to F-actin, which is required for robust nuclear import.

\section{Palladin overexpression generates F-actin hyperbundles, requiring the Ig3 domain}

Previous results have shown that overexpression of $90 \mathrm{kDa}$ palladin in cultured astrocytes or COS-7 cells results in the formation of either unusual super-robust actin bundles or star-like actin multifilament arrays. ${ }^{36,37,38}$ We used the COS-7 cell transfection protocol described above to examine the ability of palladin mutants to achieve this high level of actin organization. In COS-7 cells transfected with empty vector, a few thin stress fibers are usually observed (supplemental Fig. S7), whereas in cells expressing WT palladin, actin colocalizes with palladin in distinctive "hyper-bundled" super-robust actin-rich structures, as described previously $36,39,40$ (Fig. 4). Blind scoring of cells revealed that unusually large actin arrays are observed in $61 \%$ of cells transfected with WT palladin. Similar results were obtained when cells were transfected with palladin containing single point mutations K15A, K18A, K51A (Fig. 4 and supplemental Fig. S7); however, the double and triple point mutants generated super-robust actin bundles in only $3.7 \%$ and $9.3 \%$ of transfected cells, respectively. No super-robust bundles were observed in cells transfected with the $\Delta \operatorname{Ig} 3$ mutant. These results suggest that direct binding of palladin to F-actin is likely to be required for the generation of the distinctive palladin overexpression phenotype.

\section{Discussion}

The primary goal of this work was to determine which residues are critical for palladin to bind and bundle F-actin. This knowledge is key to understanding the molecular basis that governs palladin regulation of actin filament dynamics within the cell. Our basic approach was to determine the structure of the Ig3 domain of palladin and then to use this structure to guide mutagenesis studies. The results we have obtained provide new insight into the manner in which palladin binds to actin and crosslinks actin filaments. They also provide support for an electrostatic model for binding and bundling of F-actin by palladin.

Previous results were the first to show that the Ig3 domain of palladin is responsible for organizing actin into multi-filament arrays, thus establishing that certain sub-types of Ig domains are actin-binding modules. ${ }^{10}$ The structure of Ig3 was determined by using NMRderived constraints and reveals that the surface of this immunoglobulin fold contains two highly basic patches. Recognizing that regions of contact between actin and actin-binding proteins are often found to be rich in basic amino acids,${ }^{30}$ we assessed the functional relevance of the surface-exposed lysine residues on opposite sides of this domain. Charge neutralization variants at either site severely hindered the ability of $\operatorname{Ig} 3$ to bind F-actin; however, single mutations to either patch do not completely eliminate F-actin binding, indicating that other residues also contribute to binding of F-actin. Based on the threedimensional structure of the Ig3 domain of palladin, structure-guided mutagenesis, and biochemical and cellular studies, we show here that palladin contains two major actinbinding sites, one containing lysine 15 and 18 and another containing lysine 51. The presence of two F-actin binding patches in Ig3 also suggests that this domain may be capable of crosslinking F-actin by a mechanism involving simultaneous association of two actin filaments by a single Ig3 molecule.

Actin bundles are the primary organizational arrangement of actin in vivo and were initially shown to form only in the presence of a tandem construct containing both the Ig3 and Ig4 palladin fragments. ${ }^{10}$ However, differential co-sedimentation assays and fluorescence microscopy have revealed that Ig3 is in fact the minimal actin cross-linking fragment of palladin, and can produce significant bundles at higher concentrations of Ig3. These Ig3 
initiated F-actin bundles appear to differ structurally from the more robust bundles created by the tandem $\operatorname{Ig} 3-\operatorname{Ig} 4$ domain and further studies are underway to elucidate this difference. Mutations of either basic patch significantly reduced actin crosslinking, suggesting a critical role for both of these basic patch residues in the formation of actin bundles. This is also consistent with a two actin-binding site model, which is further supported by our data indicating that isolated Ig3 remains monomeric in solution and yet is capable of crosslinking actin filaments. While the two binding site model implies a 2:1 (G-actin:Ig3) ratio, our bundling co-sedimentation results for Ig3 support the opposite ratio (1:2). The lack of agreement between the ratio of actin to palladin that promotes binding versus that required for bundle formation, suggests the bundling mechanism is likely more complicated than a simple two binding site model and bundling may require significant decoration of actin filaments with palladin to overcome the electrostatic repulsion between filaments. Although the sedimentation equilibrium data that we present here reveals that the Ig3 and tandem Ig3Ig4 domains both remain monomeric in solution, an alternative crosslinking mechanism for full-length palladin could involve a conformational change in palladin induced by actinbinding that results in dimerization, such as that observed for vinculin. ${ }^{41}$

It is also possible that contributions from the other Ig domains as well as other residues within Ig3 of palladin may significantly alter the F-actin crosslinked structure and function. Increased actin binding affinity and bundling was observed for tandem Ig3-Ig4, with greatest affinity for full-length palladin. Likewise, palladin has multiple binding partners that also interact directly with actin: $a$-actinin, ${ }^{42}$ vasodilator stimulated phosphoprotein (VASP), ${ }^{39}$ and profiling. ${ }^{40}$ It is currently unclear how these interactions contribute to palladin's role in regulating cell motility and morphology, yet it is clear that palladin is intimately linked to actin organization both directly and indirectly.

This work highlights the importance of the Ig3 domain in binding and crosslinking of Factin via direct, electrostatically driven association. We have previously shown that the interaction between the Ig3 domain and F-actin is driven by electrostatic interactions, as Factin binding dramatically increased as the salt concentration was lowered. ${ }^{10}$ In fact many other actin-binding domains are rich in positive charge and long-range electrostatics interactions may stabilize the polyelectrolyte nature of F-actin. ${ }^{43,44} \mathrm{~A}$ detailed examination of the charge density variations on F-actin by Angelini et al. revealed that the surface of Factin contains subdomains that are strongly anionic. ${ }^{45}$ Subdomain 1 of the actin monomer is strongly anionic with a net charge of -10 , which is almost 4 times higher than the overall charge on actin. This electrostatic model for actin binding is relevant given the high density of filaments in cells as well as the presence of ionic fluxes. ${ }^{45}$ Among the significant number of actin-binding proteins with no obvious consensus F-actin binding site, the identification of proteins containing lysine-rich clusters is expanding. We suggest that the Ig3 domain of palladin be added to this list, which currently includes the DAIKKKL sequence found in actin depolymerization factor (ADF), cofilin and tropomyosin, ${ }^{46}$ the KKEK and NLKK of villin, ${ }^{47}$ KLKK of AFAP-110, KLRK in VASP, the KLKK found in thymosin $\beta 4,{ }^{30}$ KKLKH in ciboulot domains $1-3,{ }^{48}$ and KKGGKKKG sequence of myosin. ${ }^{49}$ Deletion or charge reversal mutagenesis of these basic residues in previous studies has abolished the Factin bundling activity of these proteins, suggesting that bundling occurs as a consequence of neutralization of the negatively charged F-actin surface. ${ }^{30,50}$ The specific binding sites of these proteins may be closely related to the surface charge distribution; however, this does not exclude the significance of specific actin binding sites that rely on structural features and compatible hydrophobic surfaces.

Binding studies carried out in the Hartwig and Lehman labs reveal that the immunoglobulin repeats of filamin A (FLNa) contributes significantly to the actin binding strength of FLNa. ${ }^{21}$ Moreover, they have recently put forth a model, based on 3D EM reconstruction, 
where Ig10 of FLNa binds to negatively-charged regions of F-actin. ${ }^{51}$ The FLNa residues involved in actin binding are surface-exposed, basic amino acids (four lysine and one arginine), but this binding interface has yet to be verified as important for actin binding. Several of these lysine residues in the Ig10 domain of FLNa are located in similar positions in palladin's Ig3 domain, both in primary and tertiary structure (Supplemental Fig. S9). These conserved lysine residues can also be identified in the Ig3 domain of myopalladin, which suggests a common F-actin binding interaction motif.

The results presented here show that the Ig3 domain of palladin is both necessary and sufficient for both binding and bundling of F-actin. Based on our cell-based experiments, we also suggest that this domain of palladin is directly involved in organization of the actin cytoskeleton. We have identified two clusters of basic residues on the surface of Ig3 that are required for F-actin crosslinking. Electrostatic interactions are also a major determinant in actin polymerization and many basic proteins cause both polymerization and bundling of actin filaments. Ongoing studies in our lab indicate that the Ig3 domain of palladin is also capable of inducing actin polymerization under non-polymerizing conditions, so understanding how the electrostatic interactions between actin and palladin regulate actindependent processes is a major challenge for the future. The approach we have taken and the results we have obtained provide a foundation for this type of investigation. Our cell-based experiments also reveal new details about the mechanism that regulates palladin's distinctive pattern of subcellular localization, as palladin is usually concentrated both in closely-spaced puncta arrayed along the actins stress fibers and also within the nucleus in certain cell types. ${ }^{32,33}$ Our results show that double and triple point mutations within palladin's Ig3 domain cause a redistribution of palladin from the cytoplasm to the nucleus, although a palladin mutant lacking the Ig3 domain displays a diffuse localization pattern within the cell such that the $\Delta \operatorname{Ig} 3$ mutant appears to partition equally between the cytoplasm and the nucleus. These results not only indicate that the interaction between palladin and F-actin is required to target palladin to actin-rich structures, but also suggest that a second molecular interaction, also mediated by the $\operatorname{Ig} 3$ domain, may be required in order to recruit palladin efficiently into the nucleus. Two different nuclear localization mapping tools (WoLF PSORT and cNLS Mapper Tool ${ }^{52}$ did not identify any recognizable nuclear import or export sequences, which suggests that palladin is transported into the nucleus in a complex with another protein. Previous studies have shown that the C-terminal half of palladin binds to the transcriptional regulator MRTF, ${ }^{33}$ suggesting that MRTF might be a good candidate for this role. Palladin binding partners, profilin and a-actinin-4, also localize to the nucleus; however, neither protein binds to the C-terminal region of palladin. Therefore MRTF is the most likely candidate at this point. Clearly, additional studies will be required to explore this hypothesis.

\section{Materials and Methods}

\section{Protein expression and purification}

Plasmids containing the individual Ig3, Ig4 and tandem Ig3-Ig4 cloned from (M. musculus) were previously inserted into a modified pMAL-c2x (New England BioLabs) expression vector. ${ }^{10}$ The Ig3 domain of palladin is $99-100 \%$ identical among all orthologs in mammals (Fig. S1c). Several lysine residue mutants were generated from the pMAL Ig3 construct, including K15A, K18A, K15/18A, K36A, K38A, K36/38A, K51A, and K15/18/51A. All Ig3 variants were generated using QuikChange site-directed mutagenesis (Stratagene, LaJolla, CA), with sequences verified by DNA sequencing. The palladin Ig domains were purified as previously reported. ${ }^{10}$ All Ig3 variants were examined by SDS-PAGE gel to assess purity and protein integrity before being employed in biochemical assays. 


\section{NMR data collection}

All NMR data were collected at $25^{\circ} \mathrm{C}$ on 600 and $700 \mathrm{MHz}$ Varian Unity INOVA (Palo Alto, CA) spectrometers. Pulse sequences were provided by Varian BioPack and data were processed with NMRPipe (One Moon Scientific). ${ }^{53}$ The NMR sample used for the structure determination contained $0.3-0.8 \mathrm{mM}$ protein in buffer containing $50 \mathrm{mM}$ Tris-maleate $(\mathrm{pH}$ 6.0), $150 \mathrm{mM} \mathrm{NaCl}, 2 \mathrm{mM}$ DTT, $0.01 \%$ sodium azide, and $10 \%$ deuterium oxide. All backbone and side chain assignments were previously determined and deposited (BMRB ID: 15512). ${ }^{26}$ Distance restraints were obtained from isotope-edited 3D-NOESY experiments: ${ }^{15} \mathrm{~N}$-edited $(\tau=100 \mathrm{~ms}),{ }^{54}{ }^{13} \mathrm{C}$-edited $(\tau=100 \mathrm{~ms})$ and aromatic ${ }^{13} \mathrm{C}$-edited $(\tau=150 \mathrm{~ms})$ NOESY-HSQC. ${ }^{55}$

\section{Structure calculations}

Automated NOE cross-peak assignments and structure calculations ${ }^{56}$ with torsion angle dynamics were performed using the program CYANA (version 2.2). ${ }^{28}$ Backbone torsion angle constraints obtained from database searches with the program TALOS+ were incorporated into the structure calculation. ${ }^{27}$ Simulated annealing with 20,000 torsion angle dynamics time steps per conformer was performed in the CYANA structure calculations using the default parameters. In the final cycle of the CYANA protocol, 20 conformers were generated and further refined using CS-ROSETTA. The CS-ROSETTA protocol used here is a simplified version of the RASREC (Resolution $\underline{\text { Addapted }} \underline{\mathrm{S}}$ tructural Recombination) method developed by Lange and Baker for solving NMR solution structures of proteins with low contact order. ${ }^{57}$ The Ig3 domain is a 9 -stranded $\beta$-sandwich with four non-canonical loops that cross from the top $\beta$-sheet to the bottom $\beta$-sheet. This makes Ig 3 an ideal structural candidate for the RASREC method. The RASREC method has six stages that cycle between generating Rosetta fragments, producing low energy models, and biasing conformational search space towards low energy space. Stage I of the method begins with chemical shift data, NOE constraints, and the traditional fragments used in a Rosetta protein structure prediction. If $\beta$-strands are detected in the chemical shift data or from Rosetta fragments, then all possible $\beta$-strands pairings are enumerated. In each independent trajectory $0-2 \beta$-strands pairings are enforced. In our simplified version of this protocol, we limited the possible $\beta$-strands pairings to those that are known to be present in the Ig3 domain. We specified which strands could pair (i.e. $\beta$-strand 4 is paired anti-parallel with $\beta$ strand 5); however we did not specify which residue positions were paired. The experimental data and the computational method were used to determine the specific residue pairings. This greatly reduces computational expense because we do not search topologies with known incorrect $\beta$-strand pairings but the high-resolution details of the structure are still determined by experimental data. Stages II-VI were performed as previously described ${ }^{57}$ Briefly, these stages iterate between selecting fragments and residue level $\beta$ strand pairings from the lowest energy trajectories observed. This data is then used to guide further computational protein folding trajectories. In total, greater than 1,000,000 trajectories were run to produce the final structural ensemble. Final structure ensemble quality was evaluated with PSVS ${ }^{58}$. The programs MOLMOL ${ }^{59}$ and MacPyMOL ${ }^{60}$ were used to visualize the structures. The coordinates of the 20 energy-refined CYANA conformers of Ig3 have been deposited in the PDB entry 2LQR). The chemical shifts of Ig3 were previously deposited in the BMRB entry 15512). ${ }^{26}$

\section{Actin co-sedimentation assays}

The actin binding and bundling properties of the $\operatorname{Ig} 3$ variants were assessed using an adapted actin co-sedimentation assay. ${ }^{10}$ Briefly conventional monomeric actin (G-actin) purified from rabbit muscle acetone powder ${ }^{61}$ (Sigma) was polymerized with an equal volume of $2 \mathrm{X}$ actin polymerization buffer $\left(20 \mathrm{mM}\right.$ Tris $\mathrm{pH} 8.0,200 \mathrm{mM} \mathrm{KCl}, 5 \mathrm{mM} \mathrm{MgCl}_{2}$, and $4 \mathrm{mM}$ DTT at room temperature for $30 \mathrm{~min}$. To assess binding of the Ig3 mutants with F-actin, a 
$100 \mu \mathrm{L}$ sample in $1 \mathrm{X}$ actin polymerization buffer containing actin at $10 \mu \mathrm{M}$ and varying concentration of Ig3 protein were incubated at room temperature for $1 \mathrm{~h}$. The samples were centrifuged at high speed $(150,000 \cdot g)$ in a Beckman-Coulter TLA 100 rotor for $30 \mathrm{~min}$ at $25^{\circ} \mathrm{C}$. For bundling assays, similarly prepared samples were centrifuged at low speed $(5,000$ $\cdot g$ ) to pellet bundles of actin before removing supernatant for subsequent high-speed centrifugation. The pellet was then resuspended in $100 \mu \mathrm{L}$ of $0.1 \%$ SDS buffer $(0.1 \%$ SDS, $25 \mathrm{mM}$ glycine, and $25 \mathrm{mM}$ Tris, $\mathrm{pH}$ 8.3). Actin and Ig3 proteins in both the supernatant and solubilized pellet were separated using $12 \%$ SDS-PAGE gels. Protein bands were quantified using ImageJ software 62 and reported as \% Ig3 bound in binding assays or \% F-actin for bundling assays. All binding and bundling assays were repeated at least three times.

Averaged data with standard deviation error bars are presented.

\section{Fluorescence microscopy of actin filament bundles}

Purified actin was co-polymerized at $10 \mu \mathrm{M}$ concentration and in the presence or absence of $20 \mu \mathrm{M}$ Ig 3 upon addition of an equal volume of $2 \mathrm{X}$ actin polymerization buffer $(20 \mathrm{mM}$ Tris $\mathrm{pH}$ 8.0, $200 \mathrm{mM} \mathrm{KCl}, 5.0 \mathrm{mM} \mathrm{MgCl}$, and $4 \mathrm{mM} \mathrm{DTT}$ ) and G-actin buffer (2mM Tris $\mathrm{pH}$ 8.0, $1 \mathrm{mM} \mathrm{MgCl} 2,0.5 \mathrm{mM}$ EGTA, $0.5 \mathrm{mM}$ DTT, $0.2 \mathrm{mM} \mathrm{ATP}, 0.1 \mathrm{mM} \mathrm{CaCl}_{2}$, and $0.1 \mathrm{mM}$ $\mathrm{KCl}$ ). After polymerizing for $2 \mathrm{~h}$, the actin was diluted to $1 \mu \mathrm{M}$ in $1 \mathrm{X}$ actin polymerization buffer and stained with $2.5 \mu \mathrm{L}$ of $66.6 \mu \mathrm{M}$ Alexa Fluor- 488 phalloidin. Each reaction was further diluted to a final actin concentration of $50 \mathrm{nM}$. A $5 \mu \mathrm{L}$ sample was placed between a coverslip and glass slide and visualized by epifluorescence using a Nikon TE200-U microscope with 60X objective lens and a Hamamatsu Orca-ER camera.

\section{Analytical ultracentrifugation}

Sedimentation equilibrium experiments were performed on an Optima XL-A analytical ultracentrifuge using an An50Ti rotor (Beckman Instruments, Inc.). Samples were sedimented at three different rotor speeds ( $25 \mathrm{k}, 35 \mathrm{k}$, and $37 \mathrm{k} \mathrm{rpm})$. Absorbance data were collected by scanning the sample cells at a wavelength of $280 \mathrm{~nm}$ at intervals of $0.001 \mathrm{~cm}$ in the step mode, with six averages per step. The samples were judged to be at equilibrium when at least three successive scans, each taken $2 \mathrm{~h}$ apart, were superimposable. Sedimentation equilibrium was achieved within $48 \mathrm{~h}$ for all samples. Sedimentation equilibrium profiles were edited using REEDIT (J. Lary, National Analytical Ultracentrifuge Center, Storrs, CT) to extract the data between the sample meniscus and the bottom of the sample cell. The edited files were then examined by nonlinear, least-squares (NLLS) analysis using WINNONLIN (D. Yphantis, University of Connecticut, Storrs, CT; M. Johnson, University of Virginia, Charlottesville, VA; J. Lary, National Analytical Ultracentrifuge Center, Storrs, CT).

\section{Cell culture, DNA constructs, and transfection}

COS-7 cells were maintained in DMEM (GIBCO) supplemented with 10\% FBS in the cell incubator $\left(37^{\circ} \mathrm{C}, 5 \% \mathrm{CO}_{2}\right)$. Lysine residue mutants were generated from the phrGFPIINpalladin (M. musculus isoform \#4) construct, including K15A, K18A, K15/18A, K36A, K38A, K36/38A, K51A, and K15/18/51A. All variants were generated using QuikChange site-directed mutagenesis and the same primers used previously to make mutations in Ig3 domain (Stratagene, LaJolla, CA), with sequences verified by DNA sequencing. The $\Delta \operatorname{Ig} 3$ variant of GFP palladin was generated from GFP-tagged full-length $M$. musculus palladin (isoform \#4) plasmid in phrGFP II-N vector using the procedure outlined here ${ }^{63}$ and verified by DNA sequencing. Cells were transfected with palladin expression constructs using Fugene 6 (Roche Diagnostics Corp., Indianapolis, IN, USA) according to the manufacturer's protocol and examined $24 \mathrm{~h}$ following transfection. Cells were grown on glass coverslips and fixed in 4\% paraformaldehyde in PBS, then permeabilized in $0.2 \%$ Triton X-100 and incubated with Alexa-fluor 568 phalloidin and DAPI (4',6-diamidino-2- 
phenylindole). Coverslips were examined with a Nikon TE200-U microscope with 60x objective lenses, an optional 1.5x tube lens and a Hamamatsu Orca-ER camera. Images were processed using Adobe Photoshop 7.0 (Adobe Systems Inc.). For analysis of super-robust actin bundle formation, images of transfected cells were scored independently by two observers blinded as to the cell identity, with a minimum of 20 cells per group. Nuclear localization was quantified by measuring the degree of co-localization with DAPI, using Metamorph image analysis software.

\section{Supplementary Material}

Refer to Web version on PubMed Central for supplementary material.

\section{Acknowledgments}

We would like to thank Greg Young, the NMR facility manager at UNC-CH, for his assistance in NMR data collection and Dr. Ashutosh Tripathy, Director of the UNC Macromolecular Interactions Facility, for assistance in acquisition of sedimentation equilibrium data. We also thank Dr. Richard Cheney for advice with the fluorescence microscopy of F-actin bundles, and Dr. Michael Kerber for assistance with scoring of cell phenotypes, and Dr. MinQi Lu for preparation of G-actin and other critical laboratory reagents. This work was supported by NIH grants F32 CA 139926-01 to MRB, 5RO1GM081505 and NSF MCB-1121365 to CAO and 5RO1GM080568 to SLC.

\section{Abbreviations}

Ig3

ABPs

G-actin

F-actin

CH

WH2

ADF-H

VASP

Ig

FLNa

RASREC

NLLS

RMSD

HSQC

NOE

NOESY

DAPI immunoglobulin domain 3 of palladin

actin binding proteins

globular or monomeric actin

filamentous actin

calponin homology

Wiskott-Aldrich syndrome homology

actin depolymerizing factor homology

vasodilator stimulated phosphoprotein

immunoglobulin

filamin A

resolution adapted structural recombination

non-linear least squares

root mean square deviation

heteronuclear single quantum correlation

nuclear Overhauser effect

nuclear Overhauser effect spectroscopy

4',6-diamidino-2-phenylindole

\section{REFERENCES}

1. Gimona M, Buccione R, Courtneidge SA, Linder S. Assembly and biological role of podosomes and invadopodia. Curr Opin Cell Biol. 2008; 20:235-241. [PubMed: 18337078]

2. Lambrechts A, Van Troys M, Ampe C. The actin cytoskeleton in normal and pathological cell motility. Int J Biochem Cell Biol. 2004; 36:1890-1909. [PubMed: 15203104] 
3. Rafelski SM, Theriot JA. Crawling toward a unified model of cell mobility: spatial and temporal regulation of actin dynamics. Annu Rev Biochem. 2004; 73:209-239. [PubMed: 15189141]

4. Winder SJ, Ayscough KR. Actin-binding proteins. J Cell Sci. 2005; 118:651-654. [PubMed: 15701920]

5. Gimona M, Djinovic-Carugo K, Kranewitter WJ, Winder SJ. Functional plasticity of CH domains. FEBS Lett. 2002; 513:98-106. [PubMed: 11911887]

6. Paunola E, Mattila PK, Lappalainen P. WH2 domain: a small, versatile adapter for actin monomers. FEBS Lett. 2002; 513:92-97. [PubMed: 11911886]

7. Way M, Pope B, Weeds A. Molecular biology of actin binding proteins: evidence for a common structural domain in the F-actin binding sites of gelsolin and alpha-actinin. J Cell Sci Suppl. 1991; 14:91-94. [PubMed: 1653252]

8. Poukkula M, Kremneva E, Serlachius M, Lappalainen P. Actin-depolymerizing factor homology domain: a conserved fold performing diverse roles in cytoskeletal dynamics. Cytoskeleton. 2011; 68:471-490. [PubMed: 21850706]

9. Parast MM, Otey CA. Characterization of palladin, a novel protein localized to stress fibers and cell adhesions. J Cell Biol. 2000; 150:643-656. [PubMed: 10931874]

10. Dixon RD, Arneman DK, Rachlin AS, Sundaresan NR, Costello MJ, Campbell SL, Otey CA. Palladin is an actin cross-linking protein that uses immunoglobulin-like domains to bind filamentous actin. J Biol Chem. 2008; 283:6222-6231. [PubMed: 18180288]

11. Goicoechea SM, Arneman D, Otey CA. The role of palladin in actin organization and cell motility. Eur J Cell Biol. 2008; 87:517-525. [PubMed: 18342394]

12. Auerbach D, Bantle S, Keller S, Hinderling V, Leu M, Ehler E, Perriard JC. Different domains of the M-band protein myomesin are involved in myosin binding and M-band targeting. Mol Biol Cell. 1999; 10:1297-1308. [PubMed: 10233145]

13. Linke WA. Stretching molecular springs: elasticity of titin filaments in vertebrate striated muscle. Histol Histopathol. 2000; 15:799-811. [PubMed: 10963124]

14. Okagaki T, Weber FE, Fischman DA, Vaughan KT, Mikawa T, Reinach FC. The major myosinbinding domain of skeletal muscle MyBP-C (C protein) resides in the $\mathrm{COOH}$-terminal, immunoglobulin C2 motif. J Cell Biol. 1993; 123:619-626. [PubMed: 8227129]

15. Wang K, Singer SJ. Interaction of filamin with F-actin in solution. PNAS. 1977; 74:2021-2025. [PubMed: 325564]

16. Gilbert R, Cohen JA, Pardo S, Basu A, Fischman DA. Identification of the A-band localization domain of myosin binding proteins $\mathrm{C}$ and $\mathrm{H}$ (MyBP-C, MyBP-H) in skeletal muscle. J Cell Sci. 1999; 112(Pt 1):69-79. [PubMed: 9841905]

17. Duboscq-Bidot L, Xu P, Charron P, Neyroud N, Dilanian GM, A, Bors V, Komajda M, Villard E. Mutations in the Z-band protein myopalladin gene and idiopathic dilated cardiomyopathy. Cardiovascular Res. 2008; 77:118-125.

18. Gerull B, Atherton J, Geupel A, Sasse-Klaassen S, Heuser A, Frenneaux M, McNabb M, Granzier $\mathrm{H}$, Labeit $\mathrm{S}$, Thierfelder L. Identification of a novel frameshift mutation in the giant muscle filament titin in a large Australian family with dilated cardiomyopathy. J Mol Med (Berl). 2006; 84:478-483. [PubMed: 16733766]

19. Gerull B, Gramlich M, Atherton J, McNabb M, Trombitas K, Sasse-Klaassen S, Seidman JG, Seidman C, Granzier H, Labeit S, Frenneaux M, Thierfelder L. Mutations of TTN, encoding the giant muscle filament titin, cause familial dilated cardiomyopathy. Nat Genet. 2002; 30:201-204. [PubMed: 11788824]

20. Watkins H, Conner D, Thierfelder L, Jarcho JA, MacRae C, McKenna WJ, Maron BJ, Seidman JG, Seidman CE. Mutations in the cardiac myosin binding protein-C gene on chromosome 11 cause familial hypertrophic cardiomyopathy. Nat Genet. 1995; 11:434-437. [PubMed: 7493025]

21. Nakamura F, Osborn TM, Hartemink CA, Hartwig JH, Stossel TP. Structural basis of filamin functions. JCB. 2007; 179:1011-1025. [PubMed: 18056414]

22. Bang ML, Mudry RE, McElhinny AS, Trombitas K, Geach AJ, Yamasaki R, Sorimachi H, Granzier H, Gregorio CC, Labeit S. Myopalladin, a novel 145-kilodalton sarcomeric protein with multiple roles in Z-disc and I-band protein assemblies. J Cell Biol. 2001; 153:413-427. [PubMed: 11309420] 
23. Salmikangas P, Mykkanen OM, Gronholm M, Heiska L, Kere J, Carpen O. Myotilin, a novel sarcomeric protein with two Ig-like domains, is encoded by a candidate gene for limb-girdle muscular dystrophy. Hum Mol Genet. 1999; 8:1329-1336. [PubMed: 10369880]

24. von Nandelstadh P, Gronholm M, Moza M, Lamberg A, Savilahti H, Carpen O. Actin-organising properties of the muscular dystrophy protein myotilin. Exp Cell Res. 2005; 310:131-139. [PubMed: 16122733]

25. Salmikangas P, van der Ven PF, Lalowski M, Taivainen A, Zhao F, Suila H, Schroder R, Lappalainen P, Furst DO, Carpen O. Myotilin, the limb-girdle muscular dystrophy 1A (LGMD1A) protein, cross-links actin filaments and controls sarcomere assembly. Hum Mol Genet. 2003; 12:189-203. [PubMed: 12499399]

26. Dixon RD, Campbell SL. 1H, 15N, and 13C NMR chemical shift assignments for the Ig3 domain of palladin. Biomol NMR Assign. 2008; 2:51-53. [PubMed: 19636923]

27. Cornilescu G, Delaglio F, Bax A. Protein backbone angle restraints from searching a database for chemical shift and sequence homology. J Biomol NMR. 1999; 13:289-302. [PubMed: 10212987]

28. Guntert P. Automated NMR structure calculation with CYANA. Meth Mol Biol. 2004; 278:353378.

29. Jansen S, Collins A, Yang C, Rebowski G, Svitkina T, Dominguez R. Mechanism of actin filament bundling by fascin. JBC. 2011; 286:30087-30096.

30. Qian Y, Baisden JM, Zot HG, Van Winkle WB, Flynn DC. The carboxy terminus of AFAP-110 modulates direct interactions with actin filaments and regulates its ability to alter actin filament integrity and induce lamellipodia formation. Exp Cell Res. 2000; 255:102-113. [PubMed: 10666339]

31. Taylor JM, Richardson A, Parsons JT. Modular domains of focal adhesion-associated proteins. Curr. Top. Microbiol. Immunol. 1998; 228:135-163. [PubMed: 9401205]

32. Endlich N, Schordan E, Cohen CD, Kretzler M, Lewko B, Welsch T, Kriz W, Otey CA, Endlich K. Palladin is a dynamic actin-associated protein in podocytes. Kidney Int. 2009; 75:214-226. [PubMed: 19116644]

33. Jin L, Gan Q, Zieba BJ, Goicoechea SM, Owens GK, Otey CA, Somlyo AV. The actin associated protein palladin is important for the early smooth muscle cell differentiation. PLoS ONE. 2010; 5:e12823. [PubMed: 20877641]

34. Goicoechea S, Arneman D, Disanza A, Garcia-Mata R, Scita G, Otey CA. Palladin binds to Eps8 and enhances the formation of dorsal ruffles and podosomes in vascular smooth muscle cells. $\mathrm{J}$ Cell Sci. 2006; 119:3316-3324. [PubMed: 16868024]

35. Mykkanen OM, Gronholm M, Ronty M, Lalowski M, Salmikangas P, Suila H, Carpen O. Characterization of human palladin, a microfilament-associated protein. Mol Biol Cell. 2001; 12:3060-3073. [PubMed: 11598191]

36. Boukhelifa M, Hwang SJ, Valtschanoff JG, Meeker RB, Rustioni A, Otey CA. A critical role for palladin in astrocyte morphology and response to injury. Mol Cell Neurosci. 2003; 23:661-668. [PubMed: 12932445]

37. Rachlin AS, Otey CA. Identification of palladin isoforms and characterization of an isoformspecific interaction between Lasp-1 and palladin. J Cell Sci. 2006; 119:995-1004. [PubMed: 16492705]

38. Ronty M, Taivainen A, Moza M, Otey CA, Carpen O. Molecular analysis of the interaction between palladin and alpha-actinin. FEBS Lett. 2004; 566:30-34. [PubMed: 15147863]

39. Boukhelifa M, Parast MM, Bear JE, Gertler FB, Otey CA. Palladin is a novel binding partner for Ena/VASP family members. Cell Motil Cytoskeleton. 2004; 58:17-29. [PubMed: 14983521]

40. Boukhelifa M, Moza M, Johansson T, Rachlin A, Parast M, Huttelmaier S, Roy P, Jockusch BM, Carpen O, Karlsson R, Otey CA. The proline-rich protein palladin is a binding partner for profilin. FEBS J. 2006; 273:26-33. [PubMed: 16367745]

41. Johnson RP, Craig SW. Actin activates a cryptic dimerization potential of the vinculin tail domain. J Biol Chem. 2000; 275:95-105. [PubMed: 10617591]

42. Beck MR, Otey CA, Campbell SL. Structural characterization of the interactions between palladin and alpha-actinin. J Mol Biol. 2011; 413:712-725. [PubMed: 21925511] 
43. Tang JX, Janmey PA. The polyelectrolyte nature of F-actin and the mechanism of actin bundle formation. JBC. 1996; 271:8556-8563.

44. Tang JX, Ito T, Tao T, Traub P, Janmey PA. Opposite effects of electrostatics and steric exclusion on bundle formation by F-actin and other filamentous polyelectrolytes. Biochemistry. 1997; 36:12600-12607. [PubMed: 9376366]

45. Angelini TE, Golestanian R, Coridan RH, Butler JC, Beraud A, Krisch M, Sinn H, Schweizer KS, Wong GCL. Counterions between charged polymers exhibit liquid-like organization and dynamics. PNAS. 2006; 103:7962-7967. [PubMed: 16690742]

46. Yonezawa N, Nishida E, Iida K, Yahara I, Sakai H. Inhibition of the interactions of cofilin, destrin, and deoxyribonuclease I with actin by phosphoinositides. J Biol Chem. 1990; 265:8382-8386. [PubMed: 2160454]

47. Friederich E, Vancompernolle K, Huet C, Goethals M, Finidori J, Vandekerckhove J, Louvard D. An actin-binding site containing a conserved motif of charged amino acid residues is essential for the morphogenic effect of villin. Cell. 1992; 70:81-92. [PubMed: 1623524]

48. Dominguez R. Actin-binding proteins - a unifying hypothesis. TIBS. 2004; 29:572-578. [PubMed: 15501675]

49. Yamamoto K. Identification of the site important for the actin-activated MgATPas activity of yosin subfragment-1. J Mol Biol. 1991; 217:229-233. [PubMed: 1825118]

50. Pope B, Way M, Matsudaira PT, Weeds A. Characterization of the F-actin binding domains of villin: classification of F-actin binding proteins into two groups according to their binding sites on actin. FEBS Lett. 1994; 338:58-62. [PubMed: 8307157]

51. Suphamungmee W, Nakamura F, Hartwig JH, Lehman W. Electron microscopy and 3D reconstruction reveals filamin Ig domain binding to F-actin. J Mol Biol. 2012; 424:248-256. [PubMed: 23041423]

52. Sprenger J, Fink JL, Teasdale RD. Evaluation and comparison of mammalian subcellular localization prediction methods. BMC Bioinformatics. 2006; 7(Suppl 5):S3. [PubMed: 17254308]

53. Delaglio F, Grzesiek S, Vuister GW, Zhu G, Pfeifer J, Bax A. NMRPipe: a multidimensional spectral processing system based on UNIX pipes. J Biomol NMR. 1995; 6:277-293. [PubMed: 8520220]

54. Marion D, Kay LE, Sparks W, Torchia DA, Bax A. Three-dimensional heteronuclear NMR of nitrogen-15 labeled proteins. J. Am. Chem. Soc. 1989; 111:1515-1517.

55. Muhandiram DR, Farrow NA, Xu GY, Smallcombe SH, Kay LE. A gradient 13C NOESY-HSQC experiment for recording NOESY spectra of 13C-labeled proteins dissolved in H2O. J Mag Res. 1993; 102:317-321.

56. Herrmann T, Guntert P, Wuthrich K. Protein NMR structure determination with automated NOE assignment using the new software CANDID and the torsion angle dynamics algorithm DYANA. J Mol Biol. 2002; 319:209-227. [PubMed: 12051947]

57. Lange OF, Baker D. Resolution-adapted recombination of structural features significantly improves sampling in restraint-guided structure calculation. Proteins. 2012; 80:884-895. [PubMed: 22423358]

58. Bhattacharya A, Tejero R, Montelione GT. Evaluating protein structures determined by structural genomics consortia. Proteins. 2007; 66:778-795. [PubMed: 17186527]

59. Koradi R, Billeter M, Wuthrich K. MOLMOL: a program for display and analysis of macromolecular structures. J Mol Graph. 1996; 14:51-5. 29-32. [PubMed: 8744573]

60. DeLano WL. MacPyMOL: PyMOL Enhanced for Mac OS X 1.3 edit. 2006 DeLano Scientific LLC.

61. Spudich JA, Watt S. The regulation of rabbit skeletal muscle contraction. I. Biochemical studies of the interaction of the tropomyosin-troponin complex with actin and the proteolytic fragments of myosin. J Biol Chem. 1971; 246:4866-4871. [PubMed: 4254541]

62. Abramoff MD, Magalhaes PJ, Ram SJ. Image Processing with ImageJ. Biophotonics International. 2004; 11:36-42.

63. Makarova O, Kamberov E, Margolis B. Generation of deletion and point mutations with one primer in a single cloning step. BioTechniques. 2000; 29:970-972. [PubMed: 11084856] 
64. Dolinsky TJ, Nielsen JE, McCammon JA, Baker NA. PDB2PQR: an automated pipeline for the setup, execution, and analysis of Poisson-Boltzmann electrostatics calculations. Nucleic Acids Res. 2004; 32:W665-W667. [PubMed: 15215472] 


\section{Highlights}

- Mapping of the interaction surface on palladin highlights electrostatically driven actin binding

- Binding interaction between F-actin and the Ig3 domain of palladin is critical for cellular localization

- Basic residues may be a common immunoglobulin domain interface for acidic residues on actin 
(a)

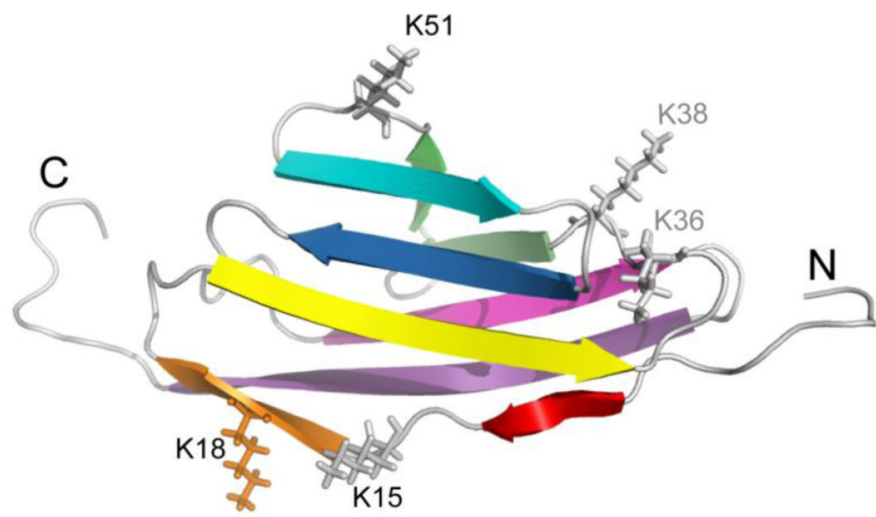

(b)

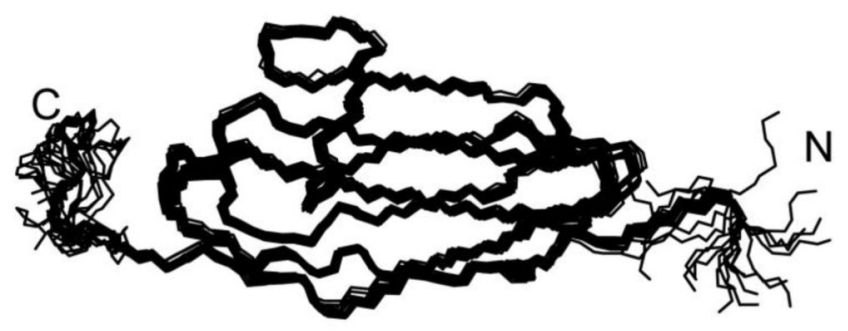

(c)

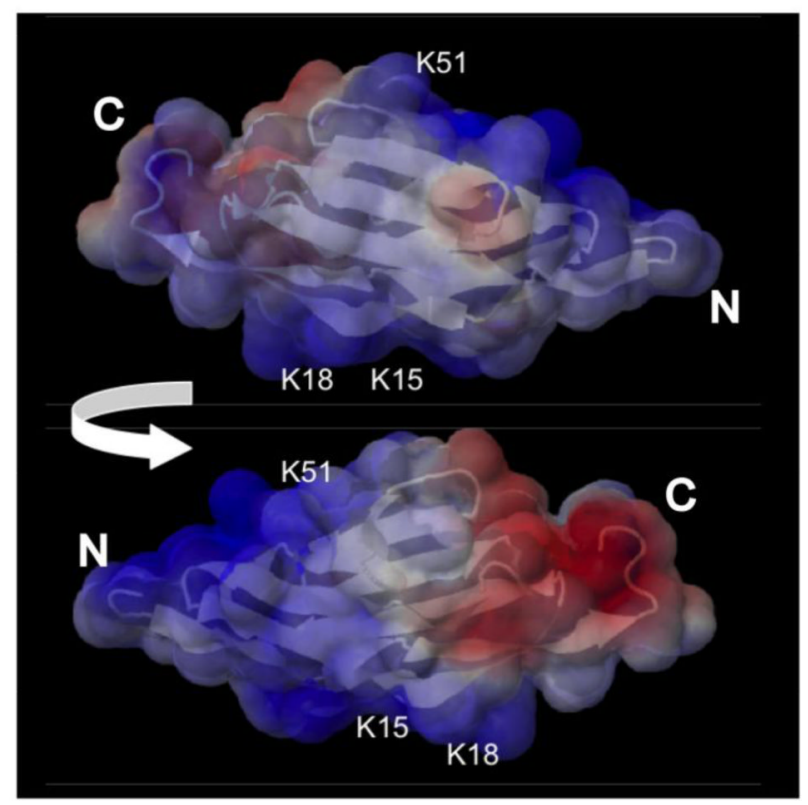

Figure 1.

NMR structure of actin-binding domain of palladin (a) Ribbon diagram of M. musculus palladin Ig3 domain, lowest energy structure from CYANA-CS-Rosetta (PDB entry 2LQR). Nine $\beta$-strands are colored from $\mathrm{N}$ to $\mathrm{C}$ termini (A, red; A', orange; $\mathrm{B}$, yellow; $\mathrm{C}$, green; $\mathrm{C}^{\prime}$, dark green; D, cyan; E, blue; F, magenta; G, purple) ${ }^{60}$ (b) Overlay of 20 lowest energy structures, ${ }^{59}$ with calculated RMSD for all ordered residues (6-100), backbone only $=0.7$ and all heavy $=1.0$. (c) Surface electrostatic potential of two faces of $\operatorname{Ig} 3$, highlighting two basic patches containing either K51 or K15/K18 (blue, positive charge; red, negative charge; and white, neutral). Charged surfaces calculated using PDB2PQR Server ${ }^{64}$. 
(a)

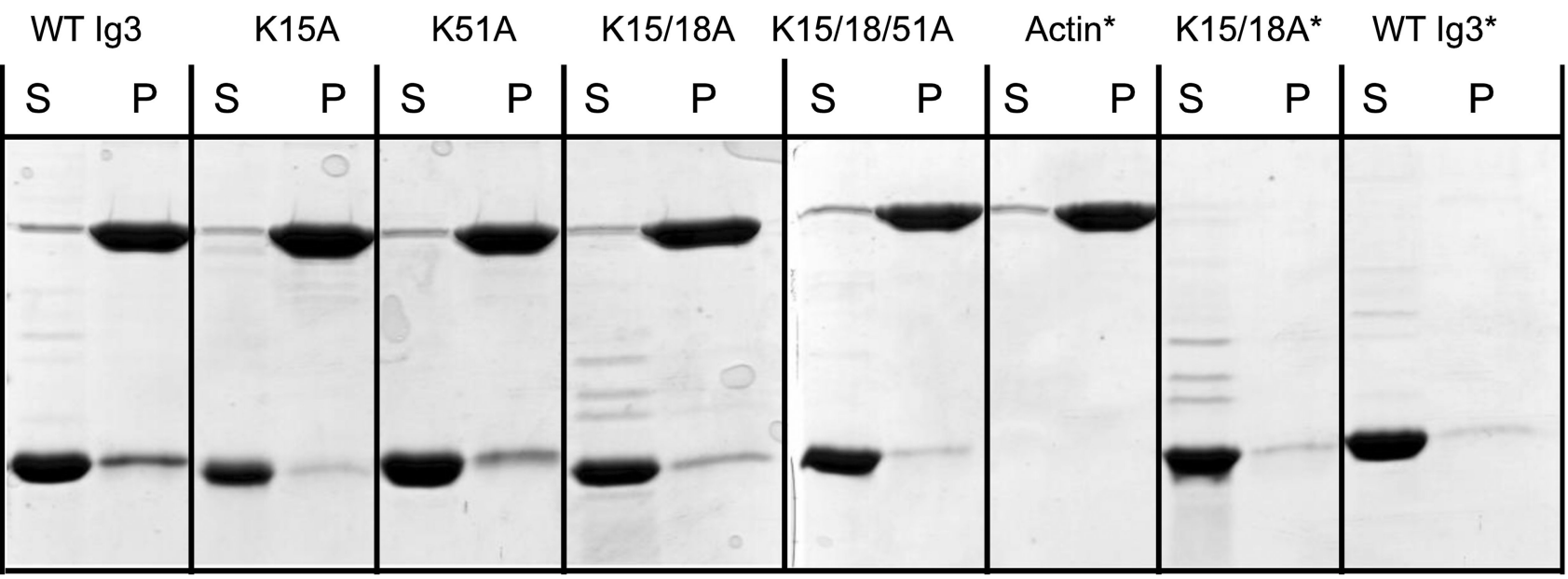

(b)

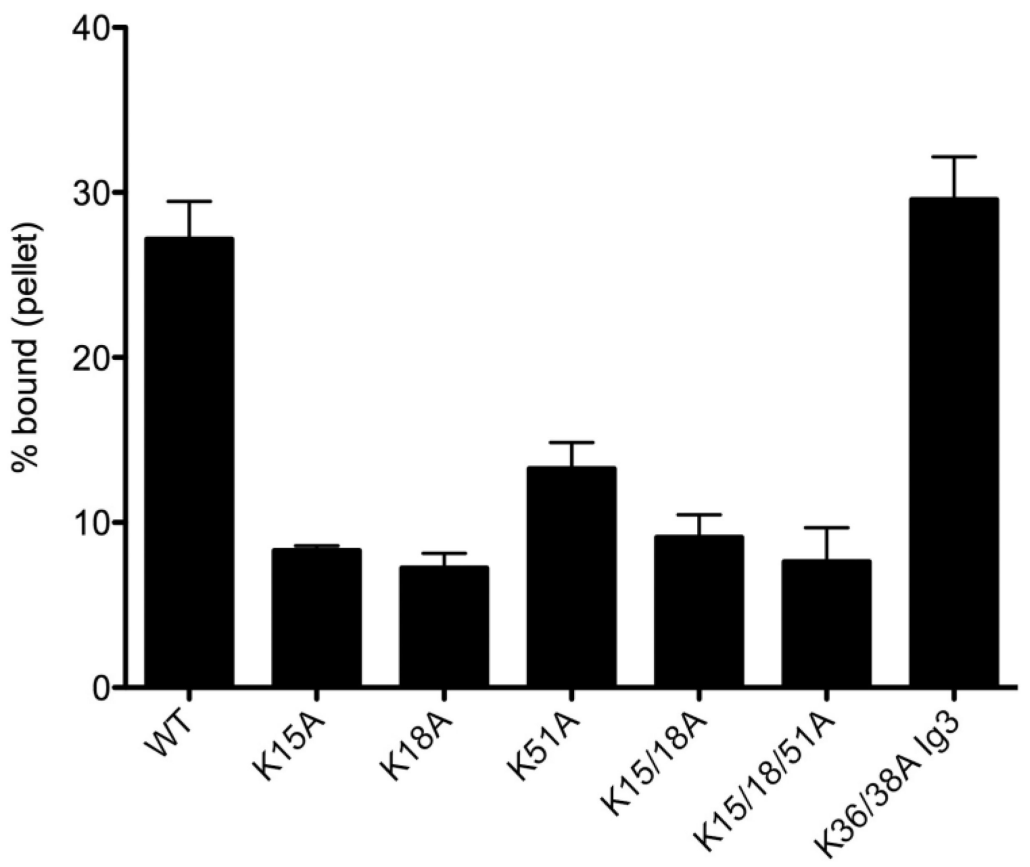

$\lg 3$ construct

Figure 2.

Basic patches on Ig3 surface are critical for binding F-actin. (a) Results of binding cosedimentation assays with F-actin, including control experiments indicated by * (actin, K15/18A, and WT Ig3 alone). Supernatant (S) and pellet (P) fractions were analyzed by gel electrophoresis. Wildtype and lysine point mutants of the Ig3 domain were purified and assayed for actin binding by co-sedimentation. Mutations of the lysine residues at residues 15, 18, and 51 all significantly reduced binding to F-actin. (b) Quantitative analysis of the amount of Ig3 bound in the presence of WT and mutant Ig3 domains. For all cosedimentation assays the $\operatorname{Ig} 3$ concentration was $10 \mu \mathrm{M}$ and actin concentration was $20 \mu \mathrm{M}$, 
and each experiment was repeated at least three times with standard deviation error bars shown. 
(a)
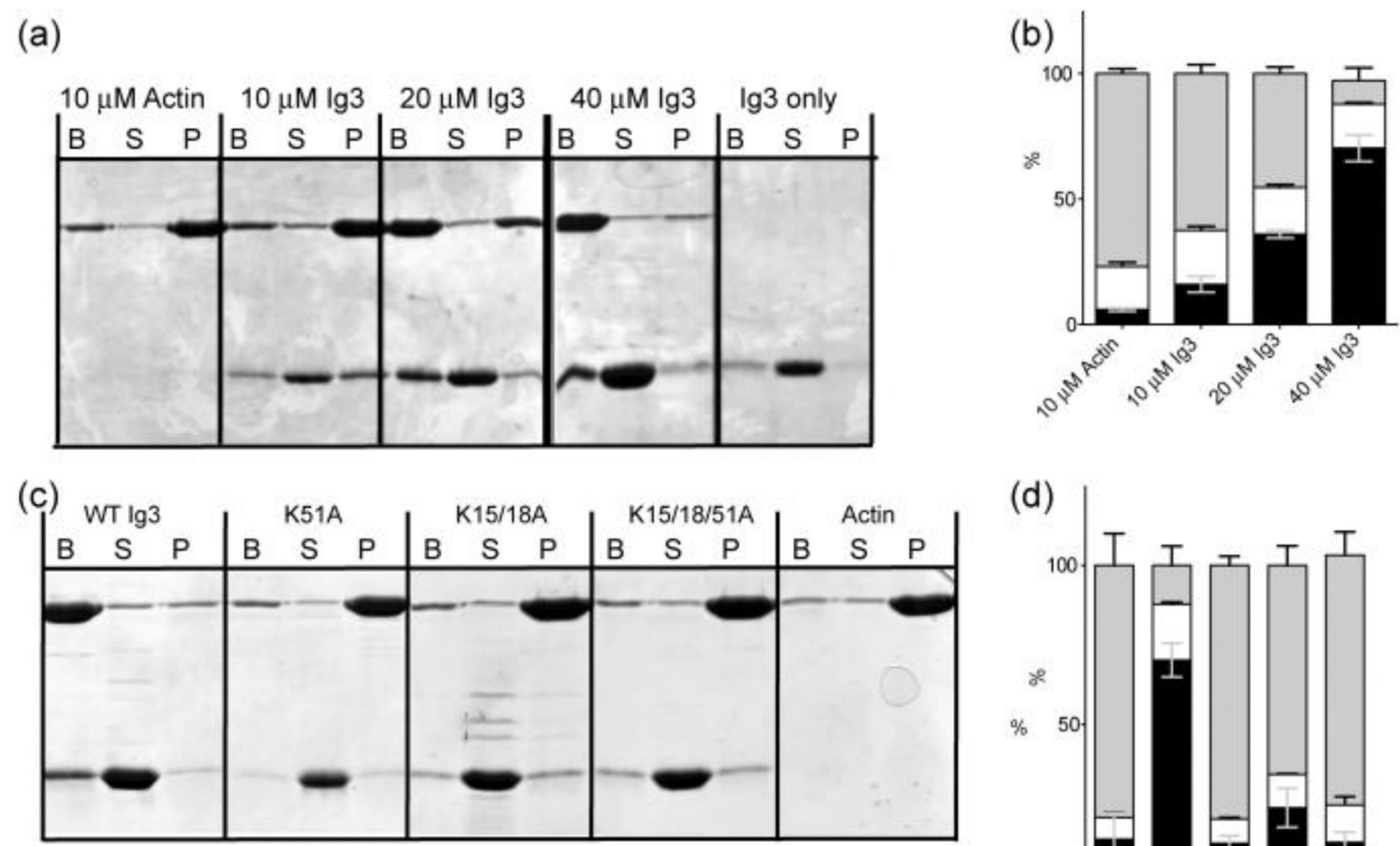

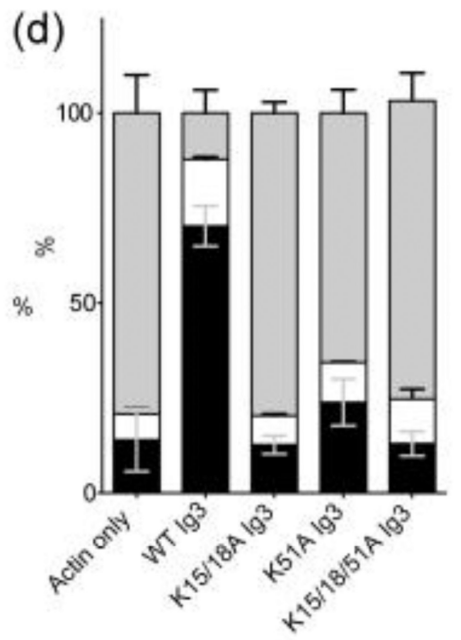

Figure 3.

F-actin bundling by Ig3 domain of palladin. Increasing the concentration of Ig 3 relative to Factin revealed that this domain is capable of bundling actin. (a) Differential centrifugation assay was used to assess crosslinking by WT Ig3, where the samples were subjected to a low speed spin, and actin bundles $(B)$ in the pellet were collected before sedimenting the remaining $\mathrm{F}$-actin by ultracentrifugation and resolving the supernatant $(S)$ and pellet $(P)$ from these spins by SDS-PAGE. (b) Quantification of actin bundling was analyzed by densitometry of the actin bands to estimate the ability of palladin to bundle F-actin. In all assays, the concentration of F-actin was held constant at $10 \mu \mathrm{M}$ and the palladin was varied from $10 \mu \mathrm{M}$ to $40 \mu \mathrm{M}$. The percent of actin found in the low speed bundle is represented by the black bar, soluble portion is white, and high speed pelleted actin is gray. (c) Wildtype and mutant forms of Ig3 domain were also assessed for actin crosslinking using the same differential centrifugation assay. Bundling assays carried out with basic lysine residues mutations (K15/18A or K51A) of Ig3 eliminate F-actin bundling by palladin. (d) Quantitative analysis of the amount of actin found in the bundle, supernatant and pellet in the presence of WT and mutant Ig3 domains. Data are means \pm standard deviation for three or more separate measurements. 


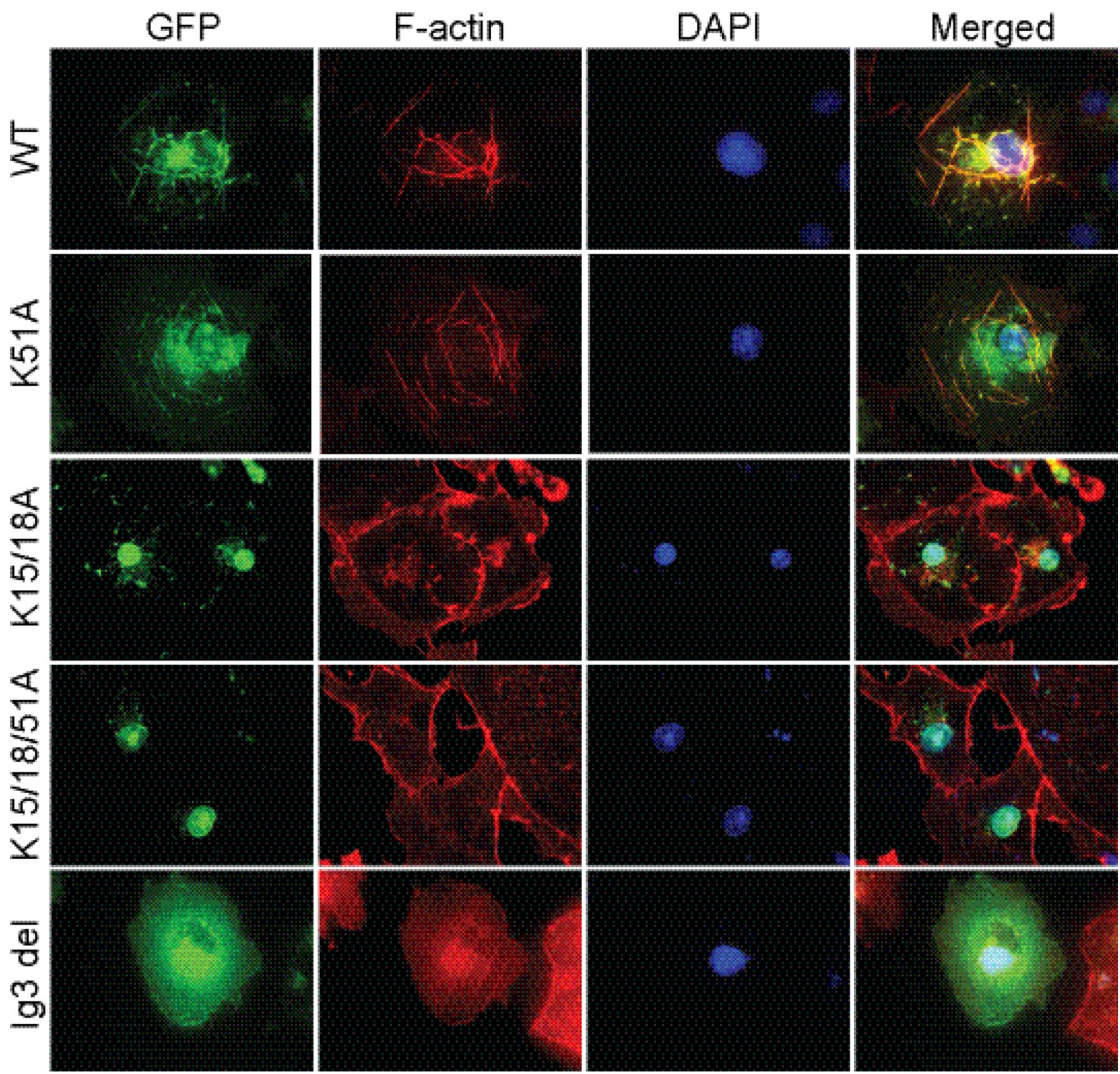

Figure 4.

Ig3 domain of palladin plays a critical role in subcellular targeting. Full-length palladin (WT), single, double and triple point mutants (K51A, K15/18A, and K15/18/51A) and Ig3 deletion mutant $(\triangle \operatorname{Ig} 3)$ were introduced into a plasmid encoding full-length GFP-tagged palladin and transfected into cultured COS-7 cells. 24 hours after transfection F-actin was stained with Alexafluor 568 phalloidin and GFP-tagged palladin variants were analyzed by fluorescence microscopy. DAPI staining was used to detect the nuclei. 


\section{Table 1}

Structural statistics of NMR structures of palladin Ig3 domain

\begin{tabular}{|c|c|}
\hline \multicolumn{2}{|l|}{ Number of distance restraints } \\
\hline Total & 1395 \\
\hline Intraresidue $(\mathrm{i}=\mathrm{j})$ & 167 \\
\hline Sequential $(|i-j|=1)$ & 330 \\
\hline Medium range $(1<|i-j|<5)$ & 150 \\
\hline Long range $(|i-j| \geq 5)$ & 748 \\
\hline Average number of constraints per residue & 13.7 \\
\hline Average number of long range distance constraints per residue & 7.3 \\
\hline \multicolumn{2}{|l|}{ Average number of distance constraint violations per conformer } \\
\hline $0.1-0.2 \AA$ & 8.5 \\
\hline $0.2-0.5 \AA$ & 12.0 \\
\hline$>0.5 \AA$ & 10.3 \\
\hline \multicolumn{2}{|l|}{ Average RMSD from mean coordinates $(\AA)$} \\
\hline Backbone atoms, all residues & 1.1 \\
\hline Backbone heavy atoms, all residues & 1.2 \\
\hline Ordered residues $b$, backbone heavy atoms & 0.7 \\
\hline Ordered residues $b$, all heavy atoms & 1.0 \\
\hline \multicolumn{2}{|l|}{ Global quality scores ${ }^{b}$ (raw/Z-score) } \\
\hline PROCHECK G-factor ( $\psi$ and $\Phi)$ & -0.56 \\
\hline PROCHECK G-factor (all dihedral angles) & -0.18 \\
\hline MOLPROBITY clash score ${ }^{c}$ & 4.82 \\
\hline \multicolumn{2}{|l|}{ Ramachandran plot summary $(\%)^{d}$} \\
\hline Most favored & 83.8 \\
\hline Additionally allowed & 16.2 \\
\hline Generously allowed & 0.0 \\
\hline Disallowed & 0.0 \\
\hline \multicolumn{2}{|c|}{$\begin{array}{l}b \text { Calibrated relative to a set of high-resolution X-ray crystal structures for which the corresponding mean structure-quality score corresponds to a } \\
\text { Z-score }=0.055 \text {. }\end{array}$} \\
\hline
\end{tabular}


Table 2

Sedimentation equilibrium reveals Ig domains remain monomeric.

\begin{tabular}{|l|l|l|}
\hline $\begin{array}{l}\text { Palladin } \\
\text { domain }\end{array}$ & $\begin{array}{l}\text { Predicted } \\
\text { monomer MW }\end{array}$ & Measured MW \\
\hline $\mathrm{Ig} 3$ & $12.0 \mathrm{kDa}$ & $11.5 \pm 2 \mathrm{kDa}$ \\
\hline $\mathrm{Ig} 4$ & 11.8 & $13.4 \pm 3$ \\
\hline $\mathrm{Ig} 34$ & 26.6 & $21.8 \pm 2$ \\
\hline
\end{tabular}

